\title{
House calls: what doctors get when they give
}

Cite as: CMAJ 2020 May19;192:E561-2. doi: 10.1503/cmaj.191474

Iris Gorfinkel: I confess. Seeing my patient Jill in her home was something l'd been putting off for over a month. There are windows in life, particularly those with unwanted views, that are preferably not peered through too often. Jill's mortality was one of these.

I am about the same age as Jill. But at 54 , it was she who had won the horrific lottery of stage IV pancreatic cancer. She had been diagnosed less than a year ago. Now, she is sallow in appearance, weighs a skeletal 70 pounds, is wheelchair bound and wears the wispy hair of those who have endured chemotherapy. Her swollen feet openly ooze. A year ago, she had been my height and weight.

She lives with her son, a grade 12 student whom she affectionately calls Pookie, in a rented basement apartment along with Pookie's father, from whom Jill had separated but who has moved in to help.

As I approach Jill's gate, I'm filled with a sense of helplessness over what I have to offer in the face of her impending death. We live in an age of electronic medical records (in fact, her record is now appearing on my smart phone) and technological advances in which patients are being asked to become accustomed to doctors looking at screens more than at them. Perhaps it is in part this backdrop that makes the prospect of a house call seem all the more intimidating, potentially useless and some ancient relic of the past. This tradition seems exceedingly limited in the face of such modernity. Yet curing Jill is no longer possible, and we are only too aware of this. I'm reminded of the writer Joyce Carol Oates' words, "I stand before you naked," no longer able to hide in the garb of offering further laboratory tests, computed tomography scans or added chemotherapy. ${ }^{1}$ Rather, what is offered is the

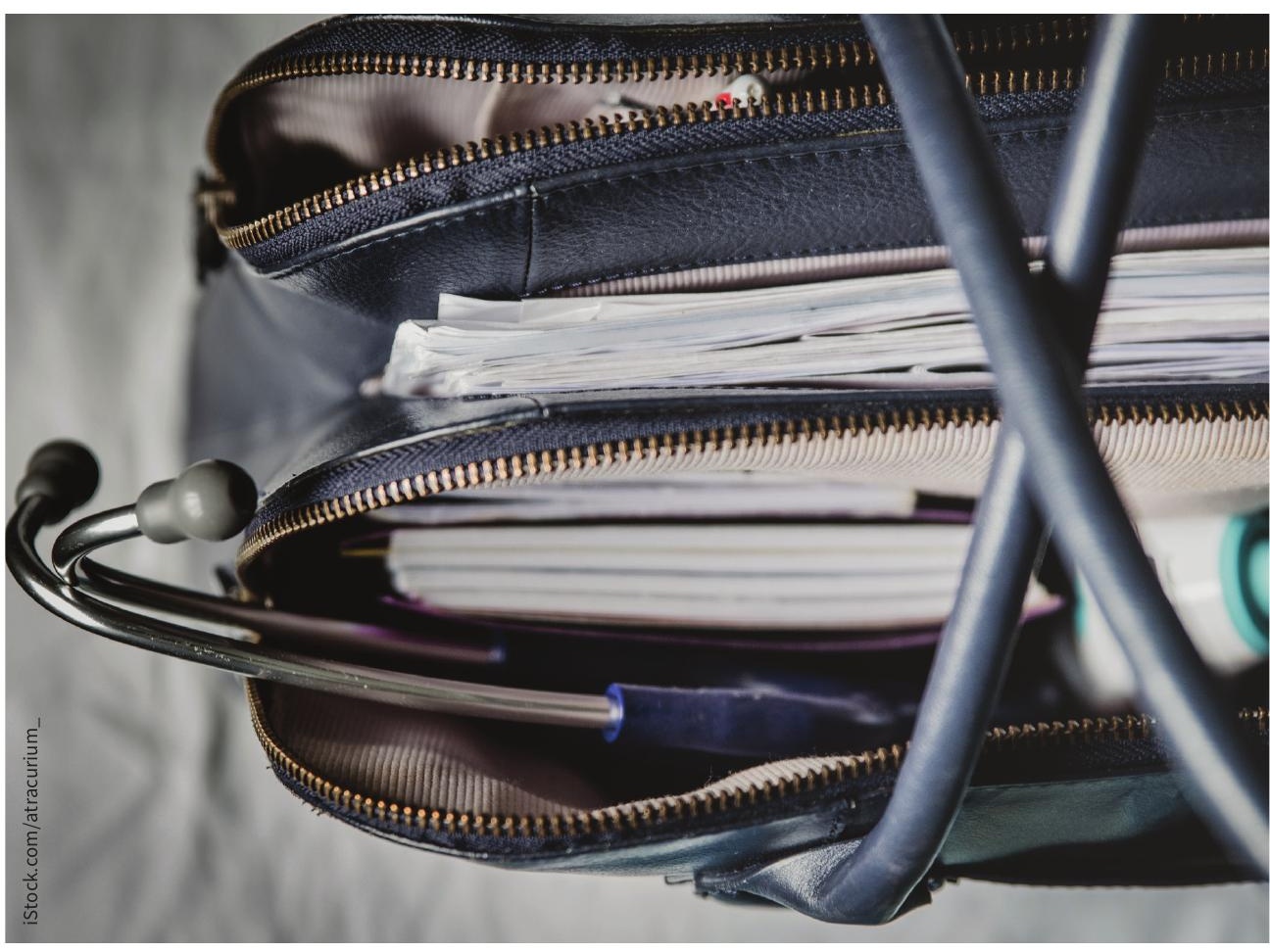

simple human connection of a family physician who has known Jill and Pookie for the past three years.

Jill is in surprisingly good spirits, which seems a stark contrast to her emaciated figure. She makes no mention of pain, weight loss, anxiety or rogue bowel movements. Instead, she proudly shows off her many rewards from having completed online surveys. Her trove includes a mini sewing machine, a bread maker and a knife set, each of which rests within an arm's distance from where we now sit chatting. She also shows me her billiards trophies and photos of her days as a horse trainer.

Despite the self-described physical, emotional and spiritual hell that Jill has endured, she has discovered purpose and found meaning in her diagnosis and throughout her aggressive treatments. I feel moved and privileged to be brought into this very private space. This includes Jill's home, her coping, her life and now her acceptance of death. And in this space, it feels all the more humbling when considering the prospect my own eventual death.

Jill then proudly tells me that there's another doctor in her life. Dr. Mark Bernstein, she explains, who is a neurosurgeon and also her palliative care doctor. He'd offered his services to her for his palliative rather than for his neurosurgical skills. I'm intrigued. The words "neurosurgeon" in combination with "house call" and "palliative" is almost beyond comprehension. It is simply unheard of. House calls historically are the purview of family physicians, many of whom have cultivated a long-standing relationship extending over years with their patients. Just who is this neurosurgeon? 
Mark Bernstein: I met Jill only five months ago, but it feels like we are old friends. I see her at home at least every week. Jill is always upbeat, lively and talkative when I visit. Maybe she is trying to put on a brave face for me and her son.

When I hug her it feels like I'm embracing a skeleton. On every visit I make sure her pain is under control; sometimes that requires adjustments to her hydromorphone pump. I also try to address all her other medical concerns like a bowel obstruction she had. We always chat about her other stuff - like her past career as a horse trainer, her old billiards awards, her current knitting projects, her latest "Farrah Fawcett" wig. She always inspires me with her courage and her equanimity.

Neurosurgery is technology driven, disease driven and cure driven. Palliative care is just about caring for the patient, connecting with them as a person and attending to more simple needs. I still find neurosurgery thrilling and exhilarating, but the home visits are intensely satisfying and give me rewards very different than those from the thrill of neurosurgery. Being trusted to come into the privacy of a patient's home, having time to get to know them as a person, getting to help them and their family at their most vulnerable time, getting to help provide them with a good death - these are all privileges that make this work intensely satisfying and something that I never take for granted for a minute.

IG: Thirty minutes later I leave Jill's home feeling as though I've taken more than I've provided. It's not supposed to be about me and yet somehow it feels as though it is. Jill seems uplifted after sharing her quest for meaning, her ongoing zest for living and her words of gratitude for having Dr. Bernstein and me involved in her care.

The very human connection with Jill, as with so many house calls, surprises me by its depth. I realize that seeing her on her own turf paradoxically delivers a degree of care in reverse. Jill's connectivity provides me with a certain clarity that ceaselessly seeing patients in an office setting so often does not. I leave feeling more connected to my work, more humbled as a human and feeling far more grateful for what generally is taken completely for granted: good health, stable finances and work that is meaningful.
It also leaves me wondering why the current dialogue on physician burnout should be so heavily problem focused. Students are warned of the high rates of burnout, depression and suicidality while the very real potential solace found in the humble house call is largely overlooked. Perhaps this focus should shift instead to our need for human connectivity, the most basic of necessities in a tradition of healing and one of medicine's greatest draws.

\section{Iris Gorfinkel MD CM}

PrimeHealth Clinical Research, Toronto, Ont.

\section{Mark Bernstein MD}

University Health Network and the Temmy Latner Cente for Palliative Care, Mount Sinai Hospital, Toronto, Ont.

\section{Reference}

1. Oates JC. I stand before you naked. New York: Samuel French; 1991.

This article has been peer reviewed.

This is a true story. Jill recently died. Her son, who holds power of attorney, consented for this story to be told. 